University of Wollongong

Research Online

Faculty of Engineering and Information

Faculty of Engineering and Information

Sciences - Papers: Part B

Sciences

2017

Performance of buried HDPE pipes - part l: peaking deflection during initial backfilling process

Min Zhou

Southeast University

Yan Jun Du

Southeast University

Fei Wang

Southeast University

Martin D. Liu

University of Wollongong, martindl@uow.edu.au

Follow this and additional works at: https://ro.uow.edu.au/eispapers1

Part of the Engineering Commons, and the Science and Technology Studies Commons

Research Online is the open access institutional repository for the University of Wollongong. For further information contact the UOW Library: research-pubs@uow.edu.au 


\title{
Performance of buried HDPE pipes - part I: peaking deflection during initial backfilling process
}

\author{
Abstract \\ Peaking deflection caused by compacting the sidefill, referred to as the maximum change of the pipe \\ diameter divided by the undeformed diameter, is an important parameter in the design and safety check \\ of buried pipelines. However, quantitative equations on the deflection useful for engineering practice are \\ very limited. In this paper, a two-dimensional finite element analysis is used to investigate the peaking \\ deflection of high-density polyethylene (HDPE) pipes. In the analyses, the pipe ¿soil interaction is rationally \\ modeled. A field trial is conducted and the finite-element modeling is evaluated by using the data \\ measured in the field test. Parametric studies are also conducted to investigate the effects of pipe \\ diameter, pipe stiffness, soil modulus, trench width, and compactor type on the peaking deflection of \\ buried HDPE pipes. A new estimating tool is developed that considers the major influencing factors: pipe \\ diameter, pipe stiffness, soil modulus, and compactor type (vibratory plate or rammer) to predict the \\ peaking deflection of HDPE pipes, and the proposed method is finally verified by data reported in \\ published studies. The comparison of the calculated and measured peaking deflections demonstrates a \\ reasonably good prediction of the peaking deflection. \\ Disciplines \\ Engineering | Science and Technology Studies

\section{Publication Details} \\ Zhou, M., Du, Y. J., Wang, F. \& Liu, M. D. (2017). Performance of buried HDPE pipes - part I: peaking \\ deflection during initial backfilling process. Geosynthetics International, 24 (4), 383-395.
}




\title{
Performance of buried HDPE pipes - part I: peaking deflection during initial backfilling process
}

\author{
M. Zhou ${ }^{1}$, Y. J. Du ${ }^{2}$, F. Wang ${ }^{3}$ and M. D. Liu ${ }^{4}$ \\ ${ }^{1}$ PhD Candidate, Institute of Geotechnical Engineering, Southeast University, Nanjing 210096, Jiangsu, \\ China, E-mail: 230139499@seu.edu.cn \\ ${ }^{2}$ Professor and Director, Institute of Geotechnical Engineering, Southeast University, Nanjing 210096, \\ Jiangsu, China, E-mail: duyanjun@seu.edu.cn (corresponding author) \\ ${ }^{3}$ Associate Professor, Institute of Geotechnical Engineering, Southeast University, Nanjing 210096, \\ Jiangsu, China, E-mail: feiwangseu@gmail.com (corresponding author) \\ ${ }^{4}$ Senior Lecturer, Faculty of Engineering and Information Sciences, University of Wollongong, \\ Wollongong, NSW 2522, Australia, E-mail: martindl@uow.edu.au
}

Received 13 July 2016, revised 05 December 2016, accepted 18 February 2017, published 18 April 2017

\begin{abstract}
Peaking deflection caused by compacting the sidefill, referred to as the maximum change of the pipe diameter divided by the undeformed diameter, is an important parameter in the design and safety check of buried pipelines. However, quantitative equations on the deflection useful for engineering practice are very limited. In this paper, a two-dimensional finite element analysis is used to investigate the peaking deflection of high-density polyethylene (HDPE) pipes. In the analyses, the pipe-soil interaction is rationally modeled. A field trial is conducted and the finite-element modeling is evaluated by using the data measured in the field test. Parametric studies are also conducted to investigate the effects of pipe diameter, pipe stiffness, soil modulus, trench width, and compactor type on the peaking deflection of buried HDPE pipes. A new estimating tool is developed that considers the major influencing factors: pipe diameter, pipe stiffness, soil modulus, and compactor type (vibratory plate or rammer) to predict the peaking deflection of HDPE pipes, and the proposed method is finally verified by data reported in published studies. The comparison of the calculated and measured peaking deflections demonstrates a reasonably good prediction of the peaking deflection.
\end{abstract}

KEYWORDS: Geosynthetics, Peaking deflection, HDPE pipe, Field trial, FE method,

Empirical formula

REFERENCE: Zhou, M., Du, Y. J., Wang, F. and Liu, M. D. (2017). Performance of buried HDPE pipes - part I: peaking deflection during initial backfilling process. Geosynthetics International, 24,

No. 4, 383-395. [http://dx.doi.org/10.1680/jgein.17.00009]

\section{INTRODUCTION}

Diameters of flexible pipes increase in the vertical direction and decrease in the horizontal direction due to the compaction of the sidefill in the initial backfilling process (i.e. the backfill is lower than the pipe top level), which is referred to as the peaking behavior (Howard et al. 1994; Fleming et al. 1997; McGrath et al. 1999; Shen et al. 2013, 2015; Wang et al. 2015; Witthoeft and Kim 2015). Consequently, the pipes deform to the shape of a vertical ellipse. The diameter change during the initial backfilling process divided by the undeformed pipe diameter is defined as the peaking deflection. The peaking deflection of a flexible pipe can reduce the deflection caused by the weight of the soil cover, which is beneficial for the long-term behaviour of the pipe under loading at the ground surface (Sargand et al. 2002, 2004; Masada and Sargand 2007; Wang et al. 2015). Arockiasamy et al. (2006) concluded that the magnitude of peaking deflection of the high-density polyethylene (HDPE) pipe in their field test is approximately equal to the pipe deflection caused by traffic loading, which indicates the importance and significance of the peaking deflection. This diametrical distortion phenomenon was also found in jacked pipes during construction (Shen et al. 2016), and steelreinforced HDPE pipes (Han et al. 2015; Khatri et al. 2015), which is controlled by the stress distribution around the pipe and would induce amounts of uncertain pipe strains. Han et al. (2013) proposed a simplified method to calculate the distributed stress on the buried structures based on the Giroud and Han (2004) method. Brachman et al. (2008) indicated that the largest deflections and 
strains are found for the HDPE pipe with uncompacted sand backfill placed below the springline. Bathurst et al. (2002) reviewed strain measurement techniques for geosynthetic materials, and indicate that strain gauges and extensometers are effective in estimating strains between 0.02 and $2 \%$ and greater than $2 \%$, respectively.

The compaction effect on the performance of flexible pipes has been investigated in previous studies through finite-element analysis (Zhang and Moore 1997; McGrath et al. 1999; Dhar et al. 2004; Masada and Sargand 2007; El-Taher and Moore 2008). McGrath et al. (1999) applied horizontal nodal forces directly onto the pipe in the FE model to simulate the compaction effect on the performance of the pipe. They found that the compactor type can significantly influence the peaking behaviour, and recommend the magnitude of nodal forces for two types of compactors (i.e. vibratory plate and rammer). Dhar et al. (2004) conducted two-dimensional finite-element (2DFE) analysis to investigate the strains and deflections of buried HDPE pipes under vertical pressure from $25 \mathrm{kPa}$ to $500 \mathrm{kPa}$. They indicated that $2 \mathrm{DFE}$ modeling is an effective tool to explore the mechanical responses of the buried HDPE pipes. El-Taher and Moore (2008) employed the 2DFE method to explore the effect of corrosion on the stability of corrugated steel culverts, and proposed a method to model the corrugated pipe as a plain structure based on the concept of equivalent pipe stiffness. Taleb and Moore (1999) proposed a technique by applying horizontal pressure onto the pipe to model the soil compaction effect in conjunction with elastic-plastic soil models to simulate the peaking behaviour. The applied horizontal pressure is equal to the passive earth pressure. They also employed the Mohr-Coulomb model with a linearly varying elastic soil modulus with depth to consider the stress-dependent soil modulus during the pipe installation process. Elshimi and Moore (2013) found that kneading of the soil could lead to its lateral expansion (i.e. plastic strains in the sidefill of the pipe) and consequently increase the vertical deflection of the pipe. They suggested that the values of the applied lateral horizontal pressures should be the passive earth pressure multiplied by the empirical kneading factor, $K_{\mathrm{n}}$, to take the soil kneading into consideration. The values of $K_{\mathrm{n}}$ are suggested as 1.0 and 2.0 for the vibratory plate compactor and the rammer compactor, respectively. In these numerical analyses, the only purpose is to simulate the compaction effect. The influencing factors of the peaking deflection have not been investigated, but are important in understanding the peaking deflection phenomenon.

Masada and Sargand (2007) proposed an analytical formula to calculate the peaking deflection as follows

$$
\Delta y / D=-\Delta x / D=\left(4.7 P_{\mathrm{c}}+K_{0} r \gamma\right) / 3.874(\mathrm{PS})
$$

where $\Delta y$ is the pipe diameter change in the vertical direction $(\mathrm{m}) ; \Delta x$ is the pipe diameter change in the horizontal direction $(\mathrm{m}) ; D$ is the undeformed diameter of the pipe $(\mathrm{m}) ; P_{\mathrm{c}}$ is the lateral pressure generated by the compactor $(\mathrm{kPa}) ; K_{0}$ is the lateral earth pressure coefficient at rest; $r$ is the radius of the undeformed pipe $(\mathrm{m}) ; \gamma$ is the unit weight of the sidefill $\left(\mathrm{kN} / \mathrm{m}^{3}\right)$, and
PS is the pipe stiffness $(\mathrm{kPa})$ defined by the following equation

$$
\mathrm{PS}=6.72 E I / r^{3}
$$

where $E$ is the Young's modulus of the pipe material $(\mathrm{kPa})$ and $I$ is the moment of inertia of the pipe wall per unit length $\left(\mathrm{m}^{4} / \mathrm{m}\right)$.

It is noted that the friction force at the pipe-soil interface and the modulus of the sidefill are not considered in the Masada and Sargand (2007) method. When these two factors are not considered, different results may be obtained in the redistribution of stresses around the pipe. This will clearly lead to errors in computing the deformation, stress, and strain of the pipe during working states. The effects of pipe-soil interface friction and modulus of the sidefill on the peaking deflection will be discussed in the subsection 'Comparison of Numerical and Measured Results' and the section 'Parametric Studies', respectively.

This paper is the first of a two-part series investigating the peaking behaviour of buried HPDE pipes during the initial backfilling process by using 2DFE modeling. A field trial is conducted and the test data are used to evaluate the numerical model. Parametric studies are made for analysing crucial factors affecting the peaking behaviour, such as pipe diameter, relative flexure stiffness (i.e. the ratio of the constrained modulus of the sidefill over the pipe stiffness), trench width, and compactor type. An empirical formula is proposed to predict the peaking deflection, and the proposed formula is verified against measured data from this study and published studies. It is seen that the proposed equation improves the accuracy of the Masada and Sargand equation, and gives a reasonably good prediction of the peaking deflection. In Part II (Zhou et al. 2017), 2DFE modeling is employed to yield an empirical formula for the total deflection of buried HDPE pipes (i.e. the pipe deflection at the end of pipe installation) with the consideration of peaking behaviour.

\section{BRIEF DESCRIPTION OF FIELD TEST}

A field trial test was conducted to investigate the field performance of HDPE pipes during the construction phase in Yixing city, China. Three double-wall corrugated HDPE pipes with a length of $6.0 \mathrm{~m}$ and two nominal diameters of 0.3 and $0.6 \mathrm{~m}$ were used in the field tests. The pipe stiffness was $215 \mathrm{kPa}$. The excavated trench width was $2.0 \mathrm{~m}$ and the soil covers were $0.9,1.0$ and $1.9 \mathrm{~m}$ in depth. Excavated in-situ soil at its optimum water content $(20.6 \%)$ was used as backfill material beside the pipe and compacted to the required degrees of compaction (Figure 1) using a vibratory plate compactor, as suggested by China Association for Engineering Construction Standardization (CECS 2004). The sand cone test was adopted to evaluate the soil density and degree of compaction for each zone according to ASTM D1556-07 to check the requirements as listed in Figure 1. Table 1 shows the measured degrees of compaction during the initial backfill process for three pipes to demonstrate 


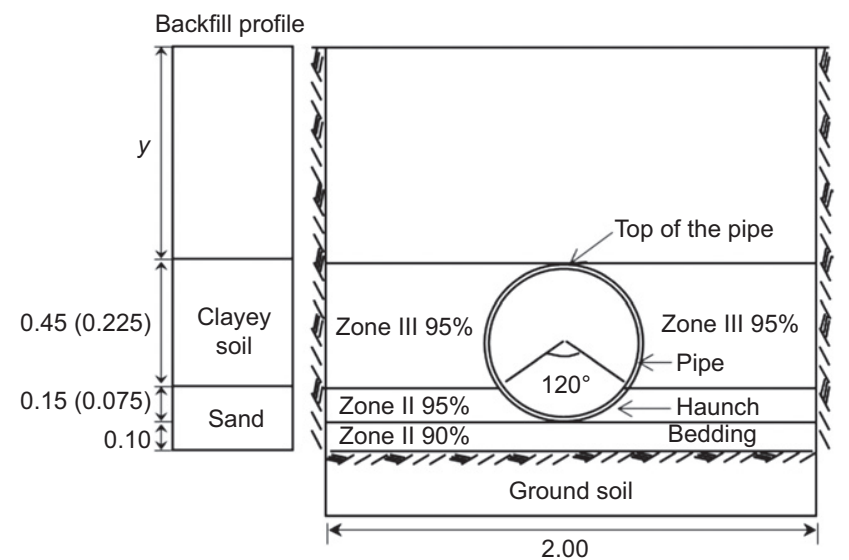

Figure 1. Required degree of compaction of the backfill around the buried HDPE pipe required during the initial backfilling process (unit: $\mathrm{m} ; y$ : soil cover thicknesses. The numbers in brackets represent the dimensions of the pipe with a diameter of $0.3 \mathrm{~m}$ )

the effectiveness of the compaction. The groundwater level was $2.5 \mathrm{~m}$ below the surface during the construction, which was lower than the trench bottom. Therefore, the groundwater effect was not considered in this study. Earth pressures around the pipes and the pipe deflections were monitored during the test. Detailed information about the field test can be found in Wang et al. (2015) and Zhou et al. (2015).

\section{VALIDATION OF NUMERICAL MODEL}

\subsection{Numerical model}

PLAXIS 2D was employed in this study to investigate the peaking behaviour of HDPE pipes. Figure 2 shows the dimension of the numerical model for the initial backfilling process of the $0.6 \mathrm{~m}$-diameter HDPE pipe. The top surface was set as stress-free to allow vertical and horizontal displacements. The side boundaries were fixed in the horizontal direction, and no constraints were applied on the vertical direction. The bottom boundary was fixed in both the vertical and the horizontal directions. As mentioned in the last section, the groundwater effect was not considered. 15-node triangular elements were adopted for the numerical model.

\subsection{Properties of materials}

PLAXIS provides a design tool, called 'tunnel designer', which can be used to create a pipe model (Shen and $\mathrm{Xu}$ 2011; Xu et al. 2012; Shen et al. 2013). In the pipe model, the pipe is treated as an elastic material with plate elements. In this study, the pipe model included 24 plate elements with each element extending for an arc length of $15^{\circ}$. It should be noted that the corrugated pipe needed to be converted to a plane pipe in the numerical modeling. Dhar et al. (2004) suggested converting the corrugated pipe to a plane pipe based on the equivalence of combined axial stiffness $(E A)$ and flexural stiffness $(E I)$, where $E$ is

Table 1. Results of sand cone tests measured during the initial backfilling process

\begin{tabular}{|l|c|c|c|c|c|c|}
\hline & \multicolumn{2}{|c|}{ P1 pipe } & \multicolumn{2}{c|}{ P2 pipe } & \multicolumn{2}{c|}{ P3 pipe } \\
\cline { 2 - 7 } & $\begin{array}{c}\text { Measured degree } \\
\text { of compaction (\%) }\end{array}$ & $\begin{array}{c}\text { Required degree of } \\
\text { compaction (\%) }\end{array}$ & $\begin{array}{c}\text { Measured degree } \\
\text { of compaction (\%) }\end{array}$ & $\begin{array}{c}\text { Required degree of } \\
\text { compaction (\%) }\end{array}$ & $\begin{array}{c}\text { Measured degree } \\
\text { of compaction (\%) }\end{array}$ & $\begin{array}{c}\text { Required degree of } \\
\text { compaction (\%) }\end{array}$ \\
\hline Zone I & 89 & 90 & 90 & 90 & 91 & 90 \\
Zone II & 94 & 95 & 93 & 95 & 95 & 95 \\
Zone III & 96 & 95 & 94 & 95 & 94 & 95 \\
\hline
\end{tabular}

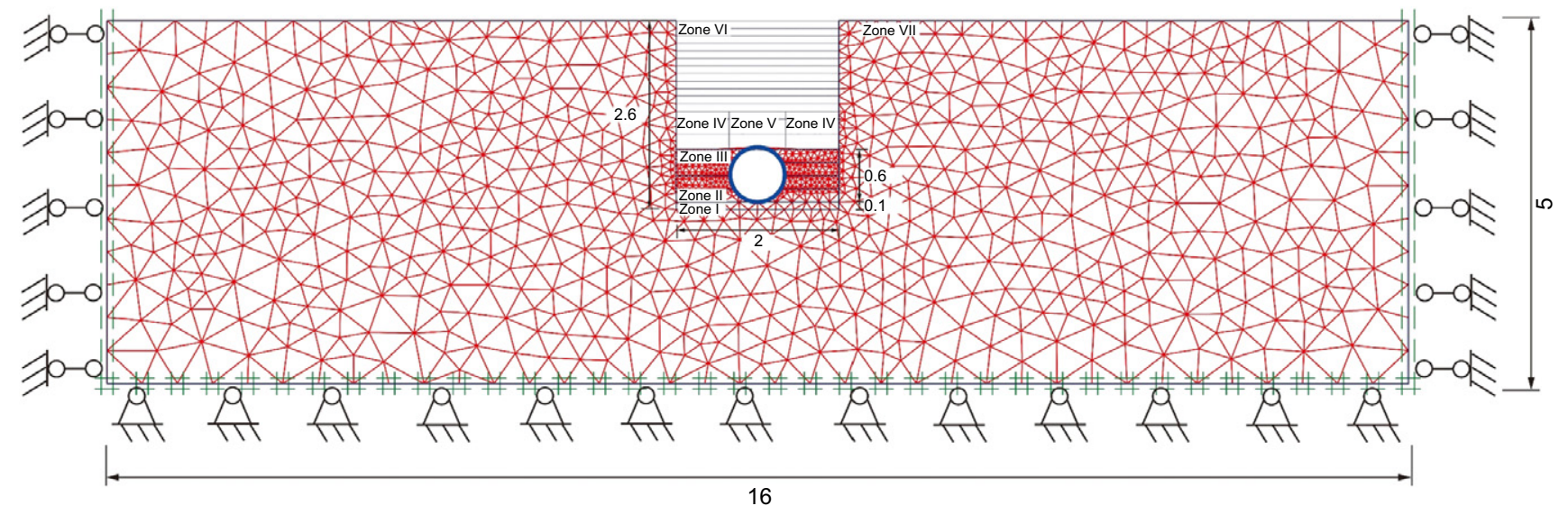

Note: Zone I to Zone III are simulated in this paper, while Zone IV to Zone VI are simulated in the companion paper.

Figure 2. Finite-element model for the initial backfilling process (Zone I and II: air-dried sand; Zone III: backfilled excavated in-situ soil; Zone VII: in-situ soil (m)) 
Table 2. Properties of backfills and HDPE pipe used for numerical model of the field test

\begin{tabular}{|l|c|c|c|c|c|c|c|}
\hline $\begin{array}{l}\text { Model } \\
\text { material }\end{array}$ & $\begin{array}{c}\text { Degree of } \\
\text { compaction (\%) }\end{array}$ & $\begin{array}{c}\text { Unit weight } \\
\left(\mathrm{kN} / \mathrm{m}^{3}\right)\end{array}$ & $\begin{array}{c}E_{0} \\
(\mathrm{MPa})\end{array}$ & $\begin{array}{c}\text { Angle of internal } \\
\text { friction }\left(^{\circ}\right)\end{array}$ & $\begin{array}{c}\text { Dilation angle } \\
\left({ }^{\circ}\right)\end{array}$ & $\begin{array}{c}\text { Cohesion } \\
(\mathrm{kPa})\end{array}$ & $\begin{array}{c}\text { Poisson's } \\
\text { ratio }\end{array}$ \\
\hline Zone I $^{\mathrm{a}}$ & 90 & 16 & 5.45 & 42 & 12 & 1.0 & 0.35 \\
Zone II $^{\mathrm{a}}$ & 95 & 16.9 & 6.44 & 48 & 18 & 1.0 & 0.40 \\
Zone III $^{\mathrm{b}}$ & 95 & 20.2 & 1.44 & 28 & 0 & 16 & 0.42 \\
Zone IV $_{\text {Zone V }}^{\mathrm{b}}$ & 90 & 19.1 & 1.09 & 28 & 0 & 13 & 0.35 \\
Zone VI $^{\mathrm{b}}$ & 85 & 18 & 0.67 & 28 & 0 & 11 & 0.3 \\
Zone VII & 95 & 20.2 & 1.44 & 28 & 0 & 16 & 0.42 \\
HDPE pipe & - & 21 & 1.25 & 28 & $\mathrm{NA}$ & 23 & 0.35 \\
\hline
\end{tabular}

${ }^{\mathrm{a}}$ Air-dried sand.

${ }^{\mathrm{b}}$ Backfilled excavated native soil.

${ }^{\mathrm{c}}$ Foundation soil above groundwater level.

${ }^{\mathrm{d}}$ Not available.

Note: Zone I to Zone III are simulated in this paper, while Zone IV to Zone VI are simulated in the companion paper.

the elastic modulus of the pipe, $A$ is the cross-sectional area of the pipe wall per unit length, and $I$ is the moment of inertia of the pipe wall per unit length. Although Siddiquee and Dhar (2015) proposed a viscoplastic model of the HDPE pipe material, the value of $E$ is taken as $520 \mathrm{MPa}$, representing a secant modulus at the termination of the pipe installation in the field trial (approximately $1 \mathrm{~h}$ ), according to the time dependent power law model developed by Chua (1986). For the determination of the values of $A$ and $I$ of the pipe wall, double-wall corrugated pipe was idealised as plate elements as per AASHTO (AASHTO 2012). Geometric properties (i.e. the $A$ and $I$ ) were determined by the integration of the areas of the corrugations. The calculated values of $A$ and $I$ were $8.6 \mathrm{~mm}^{2} / \mathrm{mm}$ and $221 \mathrm{~mm}^{4} / \mathrm{m}$ for pipe with $0.3 \mathrm{~m}$ diameter, and $14.4 \mathrm{~mm}^{2} / \mathrm{mm}$ and $1774 \mathrm{~mm}^{4} / \mathrm{mm}$ for pipe with $0.6 \mathrm{~m}$ diameter, respectively. A unit weight of $9.5 \mathrm{kN} / \mathrm{m}^{3}$ and a Poisson's ratio of 0.46 were used for the HDPE pipe, as recommended by CECS (2004) and Elshimi and Moore (2013), respectively.

The soils (i.e. backfilled sand and local soil) were modeled using an elastic-plastic soil model with the Mohr-Coulomb failure criterion. The increase in soil modulus $E$ with depth can be modeled using a linearly varying elastic soil modulus relative to a reference position, i.e., $E=E_{0}+E_{\text {increment }} z$, where $E_{0}$ is the elastic soil modulus at the reference position, which was kept at the top surface of the backfill at each step of backfill placement; $E_{\text {increment }}$ is the increase of soil modulus per unit of depth; $z$ is the depth of backfill (Taleb and Moore 1999). The elastic moduli $E$ of soils were obtained from the stress-dependent values of the constrained soil modulus $\left(M_{\mathrm{s}}\right)$ and Poisson's ratio (v) reported by McGrath et al. (1999) using the equation $E=(1+v)$ $(1-2 v) M_{\mathrm{s}} /(1-v)$. Those modulus profiles (i.e. $E$ and corresponding $z$ ) were then approximated as linear functions to determine the $E_{0}$ and $E_{\text {increment }}$. An attempt was also made to assume constant soil moduli (i.e. $E_{0}$ listed in Table 2) for all depths in the FE models to calculate the pipe deflections. The results indicate that the differences in both horizontal and vertical deflection between the cases with and without change of modulus with depth are insignificant (less than $5 \%$ ) within the range of backfill depth considered in this study. Therefore, the authors decided to use the constant soil modulus in this study for computational efficiencies. The values of the angle of internal friction and cohesion were determined from direct shear tests as per ASTM D3080-11. Strain-controlled direct shear tests were conducted on the compacted remolded native clayey soils under vertical pressures of $100,200,300$ and $400 \mathrm{kPa}$ with a shearing rate of $0.8 \mathrm{~mm} / \mathrm{min}$. The soils were compacted using a Havard compactor under the conditions of controlled water content and dry density. The water content of the samples was $20.6 \%$ and the dry density values were $1.53 \mathrm{Mg} / \mathrm{m}^{3}, 1.62 \mathrm{Mg} / \mathrm{m}^{3}$ and $1.71 \mathrm{Mg} / \mathrm{m}^{3}$, corresponding to the degrees of compaction of $85 \%, 90 \%$ and $95 \%$, respectively. The diameter and the thickness of the soil specimen were 59 and $20 \mathrm{~mm}$, respectively. The internal friction angle of the sand with a compaction degree of $90 \%$ and $95 \%$ was consistent with those suggested by Elshimi and Moore (2013). The values of the dilation angle of the backfills was determined using the angle of internal friction minus $30^{\circ}$ (Bolton 1986). The properties of the sand, backfilled clayey soil, ground soil and the HDPE pipe are listed in Table 2.

\subsection{Modeling procedure}

As shown in Figure 2, Zones I to III were backfilled to the pipe top level (i.e. the initial backfilling). Interface elements were employed to consider the friction forces at the soil-pipe interface. A strength reduction factor $\left(R_{\text {inter }}\right)$, defined as the ratio of soil strength at the interface over the soil shear strength, is used in PLAXIS (Brinkgreve 2006). $R_{\text {inter }}$ for the interface of the thermoplastic pipe and soil generally varies from 0.5 to 0.8 (O'Rourke et al. 1990; Ganesan et al. 2014; Wijewickreme et al. 2014; Ni 2016). The peaking deflections of pipes, calculated by setting $R_{\text {inter }}$ as 0.5 and 0.8 , are listed in Table 3 . It is seen that the differences between the two cases for calculated vertical and horizontal peaking deflections are insignificant, i.e., less than $5.2 \%$. Therefore, the approximate average value, 0.7 , is used in this study. It is hence suggested that this value can be used to represent the interface in practice. 
Table 3. Calculated vertical and horizontal peaking deflections of HDPE pipes

\begin{tabular}{|c|c|c|c|c|c|c|c|c|c|}
\hline \multirow[t]{2}{*}{ Pipe ID } & \multirow[t]{2}{*}{ Pipe diameter $(\mathrm{m})$} & \multirow[t]{2}{*}{ Sidefill material } & \multirow[t]{2}{*}{ Degree of compaction (\%) } & \multicolumn{2}{|c|}{$\begin{array}{l}\text { FE results } \\
\left(R_{\text {inter }}=0.5\right)\end{array}$} & \multicolumn{2}{|c|}{$\begin{array}{l}\text { FE results } \\
\left(R_{\text {inter }}=0.8\right)\end{array}$} & \multicolumn{2}{|c|}{ Relative errors } \\
\hline & & & & $\mathrm{d} y(\%)$ & $\mathrm{d} x(\%)$ & $\mathrm{d} y(\%)$ & $\mathrm{d} x(\%)$ & $\mathrm{d} y(\%)$ & $\mathrm{d} x(\%)$ \\
\hline $\mathrm{P} 1$ & 0.3 & Clayey soil & 95 & 0.39 & -0.39 & 0.4 & -0.41 & 2.5 & 5.1 \\
\hline $\mathrm{P} 2$ & 0.6 & Clayey soil & 95 & 0.38 & -0.39 & 0.4 & -0.4 & 5.2 & 2.5 \\
\hline P3 & 0.6 & Clayey soil & 95 & 0.38 & -0.39 & 0.4 & -0.4 & 5.2 & 2.5 \\
\hline
\end{tabular}

Note: $\mathrm{d} y$, vertical diameter change/un-deformed pipe diameter; $\mathrm{d} x$, horizontal diameter change/un-deformed pipe diameter.

The value of $R_{\text {inter }}$ is also set as 0.01 to simulate a scenario where the pipe-soil interface has a zero friction angle in order to address the effect of pipe-soil friction on the peak deflection of the pipes. Interface elements with an $R_{\text {inter }}$ of 0.9 were employed to simulate the interface between the trench and sidefill as suggested by Brinkgreve (2006). The pipe deflection at the end of construction of Zone III is the peaking deflection. The thickness of each lift was equal to $0.15 \mathrm{~m}$. The compaction effect was simulated by applying horizontal point loads on the lateral sides of the pipe, which was also adopted by Corey et al. (2014). Horizontal point loads were applied to the nodes of the pipe elements with an increment of $15^{\circ}$ around the pipe. It is calculated by integrating the horizontal pressure obtained from Equation 3 within the arc length of each pipe element (Corey et al. 2014).

$$
\sigma_{\mathrm{h}}=\sigma_{\mathrm{v}} K_{\mathrm{p}} K_{\mathrm{n}}
$$

where $\sigma_{\mathrm{h}}$ is the horizontal pressure imposed on the pipe side $(\mathrm{kPa}), \sigma_{\mathrm{v}}$ is the soil layer overburden pressure $(\mathrm{kPa})$, $K_{\mathrm{p}}$ is the passive earth pressure coefficient, and $K_{\mathrm{n}}$ is the kneading factor. The value of $K_{\mathrm{n}}$ is set as 1.0 and 2.0 to simulate the soil compaction using the vibratory plate and rammer compactor, respectively, as suggested by Elshimi and Moore (2013). In the numerical models of this study, $K_{\mathrm{p}}$ of the first soil layer and second to fourth soil layers at the lateral side of the pipe were 6.79 and 2.77 , respectively, determined using the internal friction angles of $48^{\circ}$ and $28^{\circ}$ (Table 2). The $K_{\mathrm{n}}$ is set as 1.0 , as suggested by Elshimi and Moore (2013), since the vibratory plate was used in the field trial. The tension cut-off technique, with a maximum allowable tensile stress of zero, was activated to remove any possible tensile stresses of the soil. The point loads were not removed in the subsequent steps.

The modeling procedure is summarised as follows.

(1) Create the numerical model and set the boundary and initial conditions.

(2) Input the properties of materials.

(3) Excavate the pipe trench with a width of $2 \mathrm{~m}$ and a depth based on the pipe diameter and the thickness of the soil cover.

(4) Activate the pipe model.

(5) Backfill the first layer material (Zone I in Figure 1) and apply horizontal point loads onto the pipe.

(6) Repeat Step 5 until the sidefill reaches the pipe top level.

\subsection{Comparison of numerical and measured results}

A comparison of the measured and calculated peaking deflections of HDPE pipes in both vertical and horizontal directions is shown in Table 4. The calculated peaking deflections of HDPE pipes agree well with the measured peaking deflections, with relative errors of less than $8 \%$ for the vertical deflection and less than $5 \%$ for the horizontal deflection. The comparison demonstrates that the numerical model adopted in this study is effective in simulating the peaking behaviour of HDPE pipes. In addition, the peaking deflection of the pipe with a smooth pipe-soil

Table 4. Vertical and horizontal peaking deflections of HDPE pipes measured in the field trial and calculated by the FE modeling

\begin{tabular}{|c|c|c|c|c|c|c|c|c|c|c|c|c|c|}
\hline \multirow[t]{2}{*}{$\begin{array}{l}\text { Pipe } \\
\text { ID }\end{array}$} & \multirow[t]{2}{*}{$\begin{array}{c}\text { Pipe } \\
\text { diameter } \\
\text { (m) }\end{array}$} & \multirow[t]{2}{*}{$\begin{array}{l}\text { Sidefill } \\
\text { material }\end{array}$} & \multirow[t]{2}{*}{$\begin{array}{c}\text { Degree of } \\
\text { compaction } \\
(\%)\end{array}$} & \multicolumn{2}{|c|}{ Field data } & \multicolumn{2}{|c|}{$\begin{array}{l}\text { FE results (with } \\
\text { pipe-soil } \\
\text { interface } \\
\text { friction) }\end{array}$} & \multicolumn{2}{|c|}{$\begin{array}{c}\text { Relative errors } \\
((\text { FE results-Field } \\
\text { data)/Field } \\
\text { data } \times 100 \%)^{\mathrm{b}}\end{array}$} & \multicolumn{2}{|c|}{$\begin{array}{c}\text { FE results } \\
\text { (without pipe-soil } \\
\text { interface } \\
\text { friction) }^{\mathrm{c}}\end{array}$} & \multicolumn{2}{|c|}{$\begin{array}{c}\text { Relative errors } \\
((\text { FE results-Field } \\
\text { data }) / \text { Field } \\
\text { data } \times 100 \%)^{\mathrm{d}}\end{array}$} \\
\hline & & & & $\mathrm{d} y(\%)$ & $\mathrm{d} x(\%)$ & $\mathrm{d} y(\%)$ & $\mathrm{d} x(\%)$ & $\mathrm{d} y(\%)$ & $\mathrm{d} x(\%)$ & $\mathrm{d} y(\%)$ & $\mathrm{d} x(\%)$ & $\mathrm{d} y(\%)$ & $\mathrm{d} x(\%)$ \\
\hline $\mathrm{P} 1$ & 0.3 & Clayey & 95 & 0.3 & -0.40 & 0. & -0 & 2.5 & 2. & 0.33 & -0.33 & 18 & 21 \\
\hline $\mathrm{P} 2$ & 0.6 & Clayey soil & 95 & 0.40 & -0.41 & 0.39 & -0.39 & 2.6 & 5. & 0.36 & -0.35 & 11 & 17 \\
\hline P3 & 0.6 & Clayey soil & 95 & 0.42 & -0.40 & 0.39 & -0.39 & 7.7 & 2.5 & 0.36 & -0.35 & 17 & 14 \\
\hline
\end{tabular}

${ }^{\mathrm{a}} R_{\text {inter }}$ is set as 0.7 .

${ }^{\mathrm{b}}$ Considering pipe-soil interface friction.

${ }^{\mathrm{c}} R_{\text {inter }}$ is set as 0.01 .

${ }^{\mathrm{d}}$ Without considering pipe-soil interface friction.

Note: $\mathrm{d} y$, vertical diameter change/un-deformed pipe diameter; $\mathrm{d} x$, horizontal diameter change/un-deformed pipe diameter. Positive values represent diameter increase and negative ones denote diameter decrease. 
Table 5. Parameters used in the parametric studies

\begin{tabular}{|c|c|c|c|c|c|c|}
\hline Case number & Pipe diameter (m) & Pipe stiffness $(\mathrm{kPa})$ & Sidefill material ${ }^{\mathrm{a}}$ & Soil modulus (MPa) & Trench width (m) & Kneading factor $^{b}$ \\
\hline $1 *$ & 0.3 & 215 & SW85 & 2.56 & 2.0 & 1.0 \\
\hline 2 & 0.6 & 215 & SW85 & 2.56 & 2.0 & 1.0 \\
\hline 3 & 0.8 & 215 & SW85 & 2.56 & 2.0 & 1.0 \\
\hline 4 & 1.2 & 215 & SW85 & 2.56 & 2.0 & 1.0 \\
\hline 5 & 0.3 & 107 & SW85 & 2.56 & 2.0 & 1.0 \\
\hline 6 & 0.3 & 339 & SW85 & 2.56 & 2.0 & 1.0 \\
\hline 7 & 0.3 & 430 & SW85 & 2.56 & 2.0 & 1.0 \\
\hline 8 & 0.3 & 672 & SW85 & 2.56 & 2.0 & 1.0 \\
\hline 9 & 0.3 & 860 & SW85 & 2.56 & 2.0 & 1.0 \\
\hline 10 & 0.3 & 215 & SW95 & 6.44 & 2.0 & 1.0 \\
\hline 11 & 0.3 & 215 & CL95 & 1.44 & 2.0 & 1.0 \\
\hline 12 & 0.3 & 215 & SW85 & 2.56 & 0.8 & 1.0 \\
\hline 13 & 0.3 & 215 & SW85 & 2.56 & 1.2 & 1.0 \\
\hline 14 & 0.3 & 215 & SW85 & 2.56 & 1.6 & 1.0 \\
\hline 15 & 0.3 & 215 & SW85 & 2.56 & 2.0 & 2.0 \\
\hline
\end{tabular}

*baseline case.

${ }^{\mathrm{a}} \mathrm{SW} 85$, well-graded sand with degree of compaction of $85 \%$; SW95, well-graded sand with degree of compaction of $95 \%$; CL95, low plasticity clay with degree of compaction of $95 \%$.

${ }^{\mathrm{b}}$ Kneading factor: $1.0=$ vibratory plate compactor; $2.0=$ rammer.

Table 6. Properties of the backfill materials

\begin{tabular}{|l|c|c|c|c|c|c|c|}
\hline $\begin{array}{l}\text { Model } \\
\text { material }\end{array}$ & $\begin{array}{c}\text { Unit weight } \\
\left(\mathrm{kN} / \mathrm{m}^{3}\right)\end{array}$ & $\begin{array}{c}\text { Degree of } \\
\text { compaction (\%) }\end{array}$ & $\begin{array}{c}E_{0} \\
(\mathrm{MPa})\end{array}$ & $\begin{array}{c}\text { Angle of internal } \\
\text { friction }\left({ }^{\circ}\right)\end{array}$ & $\begin{array}{c}\text { Dilation angle } \\
\left({ }^{\circ}\right)\end{array}$ & $\begin{array}{c}\text { Cohesion } \\
(\mathrm{kPa})\end{array}$ & $\begin{array}{c}\text { Poisson's } \\
\text { ratio }\end{array}$ \\
\hline SW85 & 15 & 85 & 2.65 & 38 & 8 & 1.0 & 0.26 \\
SW95 & 16.9 & 95 & 6.44 & 48 & 12 & 1.0 & 0.40 \\
CL95 & 20.2 & 95 & 1.44 & 28 & 0 & 15 & 0.42 \\
\hline
\end{tabular}

interface (i.e. zero friction) was calculated and compared to the field data (Table 4). It is seen that the calculated peaking deflections are $11 \%$ to $21 \%$ smaller than the measured ones, which indicates that the friction force at the pipe-soil interface has a significant effect on the peaking deflection.

\section{PARAMETRIC STUDIES}

The peaking behaviour of flexible pipes is influenced by several factors, such as pipe diameter, pipe stiffness, soil modulus, trench width, and compactor type (Marston and Anderson 1913; Sargand et al. 2001, 2002; Elshimi and Moore 2013; Wang et al. 2015). Fifteen cases with variations of the above mentioned parameters were conducted in the parametric studies. The variation of the geometrical and mechanical parameters is summarised in Table 5. Linear soil properties with an elastic modulus of $7 \mathrm{MPa}$, Poisson's ratio of 0.4 and unit weight of $18.7 \mathrm{kN} / \mathrm{m}^{3}$ reported by McGrath et al. (1999) for undisturbed clayey soil were employed for the trench soil. The ranges of pipe diameter $(0.3 \mathrm{~m}$ to $1.2 \mathrm{~m})$ and pipe stiffness $(107 \mathrm{kPa}$ to $860 \mathrm{kPa})$ are consistent with those outlined by CECS (2004). Sand and gravel are adopted as the backfill materials for buried pipes as recommended by CECS (2004) and ASTM D2321-11. However, sand and gravel may not be available in some areas where local soil with low plasticity can also be used as a backfill material, as suggested by CECS (2004). In addition, compaction is another essential factor for the soil modulus. Soil moduli vary significantly with degree of compaction (McGrath et al. 1999; Sargand et al. 2001, 2002). Therefore, the soil modulus is considered to be dependent on the type of material and the degree of compaction. Three types of backfill materials suggested by ASTM D2321-11 and CECS (2004) were adopted in the parametric studies, namely SW85 (i.e. well-graded sand with a degree of compaction of $85 \%$ ), SW95 (i.e. well-graded sand with a degree of compaction of $95 \%$ ), and CL95 (i.e. low plasticity clay with a degree of compaction of $95 \%$ ). The soil properties of SW85, SW95 and CL95 are tabulated in Table 6.

Relative flexure stiffness $\left(S_{\mathrm{f}}\right)$, a function of pipe stiffness and the constrained modulus of the sidefill defined by McGrath et al. (2002), is widely used to analyse the combined effects of pipe stiffness and the soil modulus as follows

$$
S_{\mathrm{f}}=6.72 M_{\mathrm{s}} / \mathrm{PS}
$$

where $M_{\mathrm{s}}$ is the constrained soil modulus ( $\mathrm{kPa}$ ); and PS is the pipe stiffness $(\mathrm{kPa})$.

The values of $S_{\mathrm{f}}$ were calculated as 101, 431, and 115 for SW85, SW95, and CL 95, respectively. Two types of compactors (i.e. vibratory plate compactor and rammer compactor) were used to investigate the effect of the compactor type on the peaking behaviour, which is represented by the kneading factor. The kneading factor 


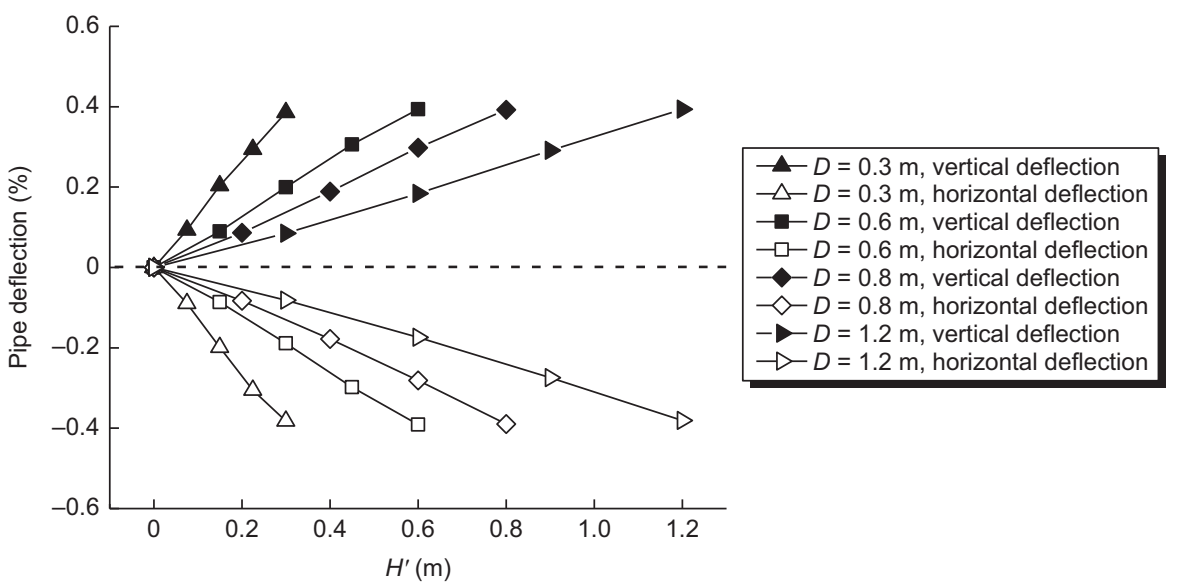

(a)

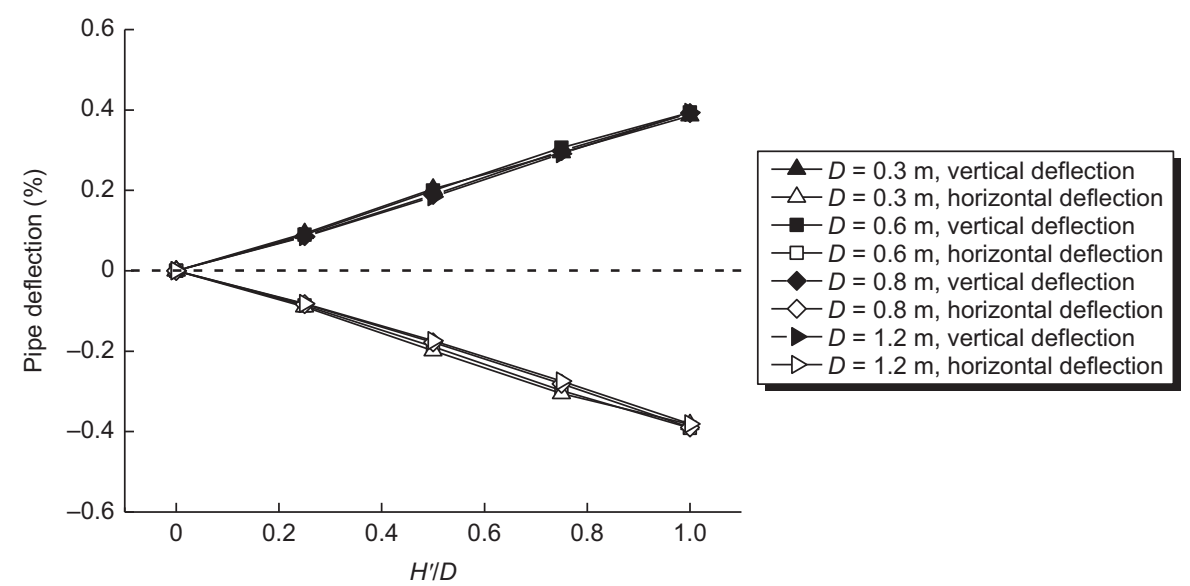

(b)

Figure 3. Effect of pipe diameter $(D)$ on the pipe deflections via FE simulations

was assumed to be 1.0 for the vibratory plate compactor, and 2.0 for the rammer.

Figures $3 a$ and $3 b$ show the effect of pipe diameter on the pipe deflection during the initial backfilling. A pipe stiffness of $215 \mathrm{kPa}$ and sidefill material of SW85 were employed to investigate the effect of the pipe diameter on the pipe deflection during the initial backfilling process. It is seen from Figure $3 \mathrm{a}$ that the peaking deflections in the vertical and horizontal directions decreased significantly with an increase of the pipe diameter. However, the effect of pipe diameter on the pipe deflection can be eliminated by using a normalised sidefill thickness (i.e. $H^{\prime} / D$ ), as shown in Figure 3b. It is seen that both the vertical and the horizontal deformation are essentially the same with $H^{\prime} / D$, with less than $0.5 \%$ difference. For the sake of analysis, $H^{\prime} / D$ is used as the horizontal coordinate in Figures 4-7.

Figure 4 presents the effect of pipe stiffness on the pipe deflection during the initial backfilling process. This figure shows that higher pipe stiffness results in smaller

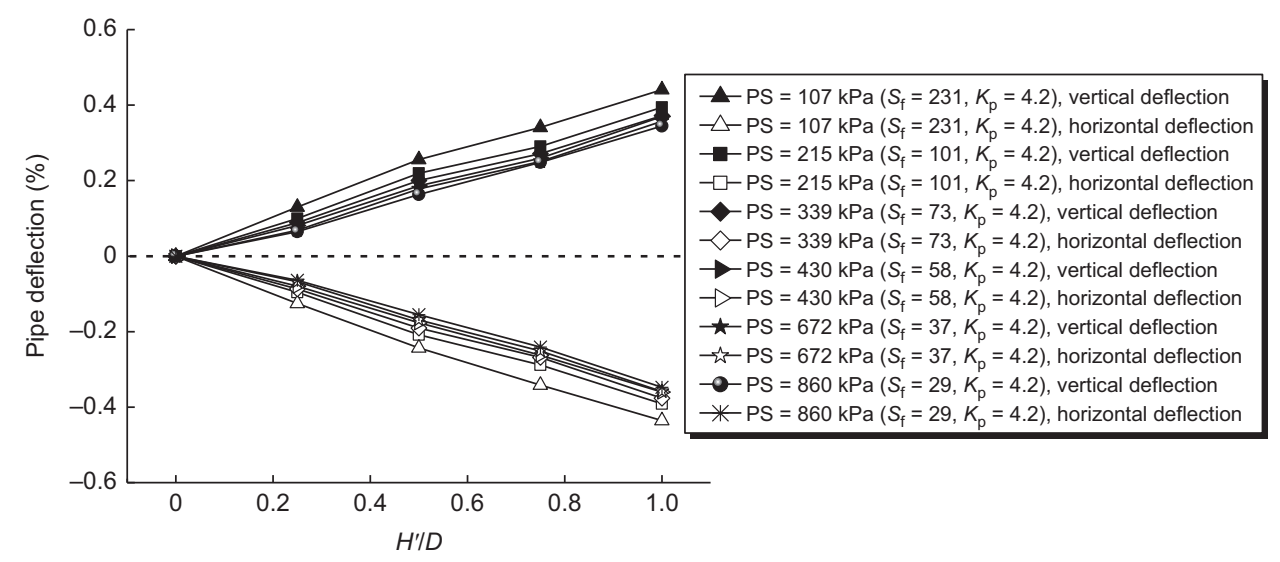

Figure 4. Effect of pipe stiffness (PS) on the pipe deflections via FE simulations 


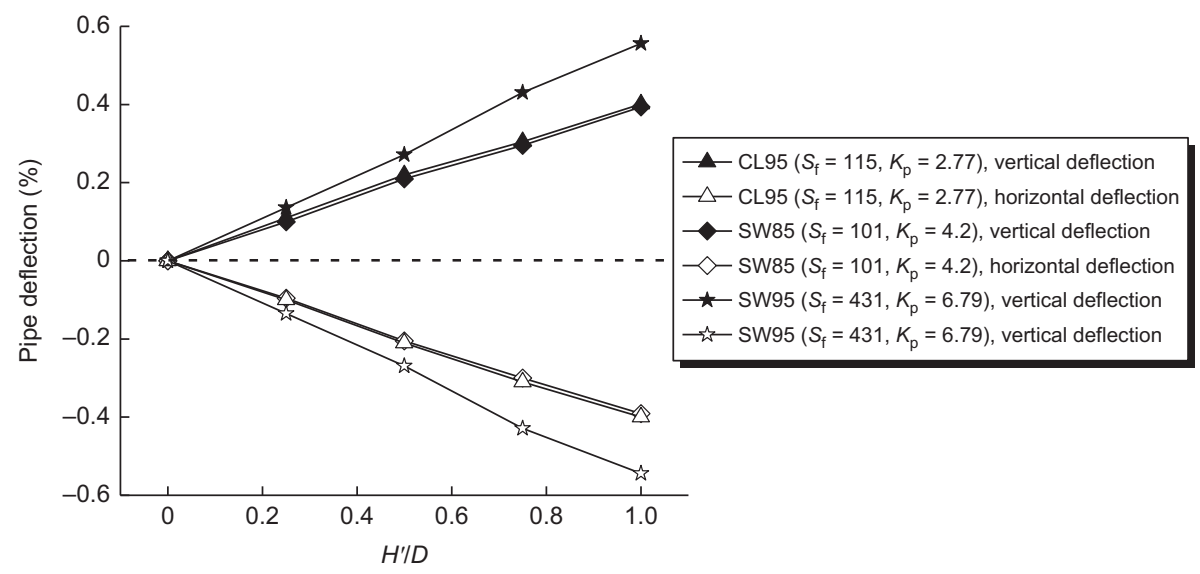

Figure 5. Effects of the sidefill type and the degree of compaction on the pipe deflections via FE simulations (CL, lean clay; SW, well-graded sand)

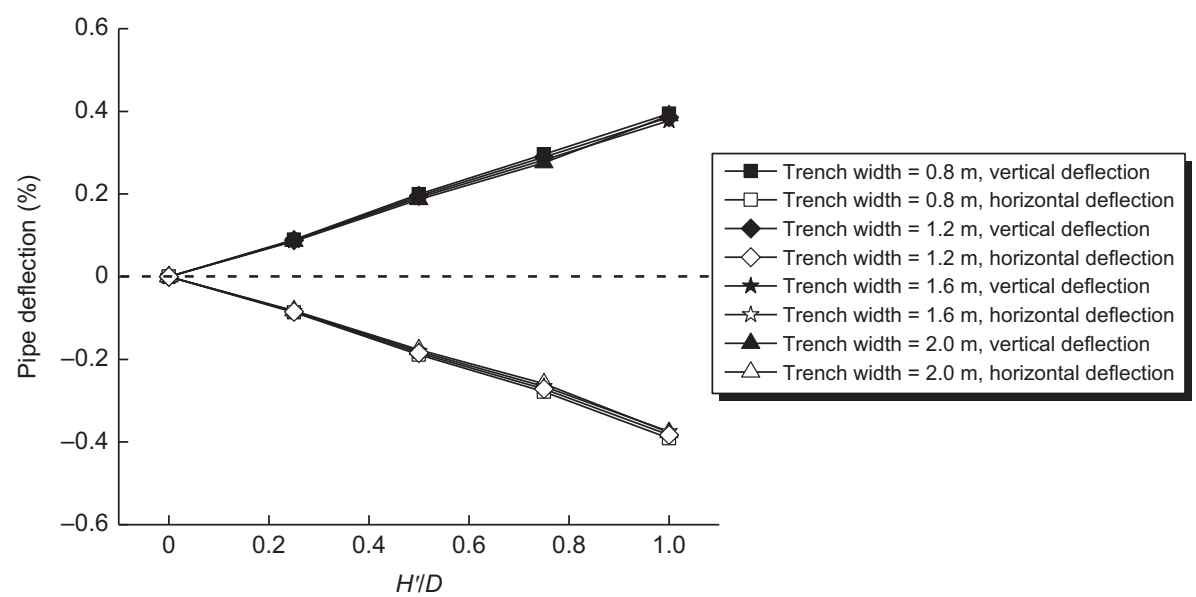

Figure 6. Effect of trench width on the pipe deflections via FE simulations

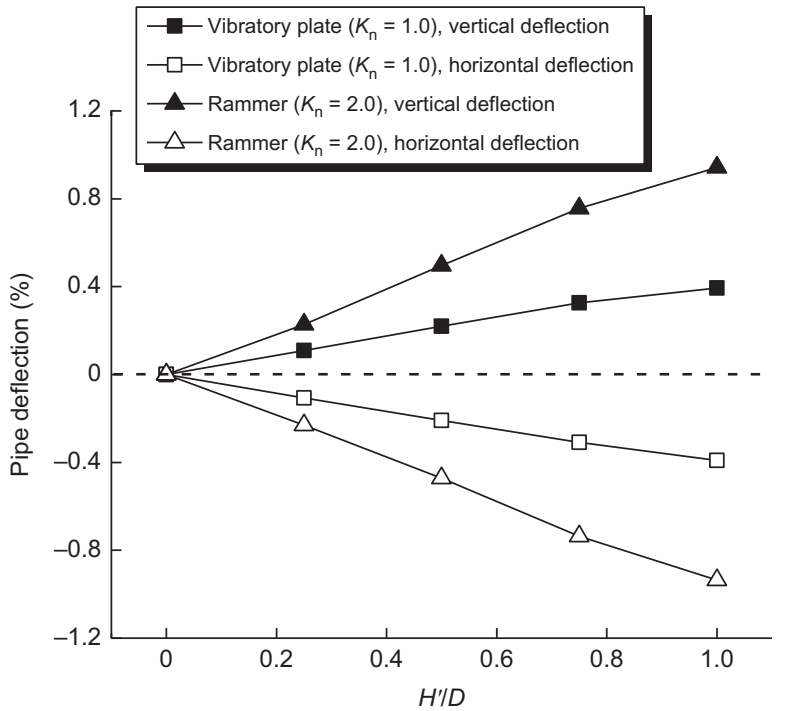

Figure 7. Effect of compactor type on the pipe deflections via FE simulations

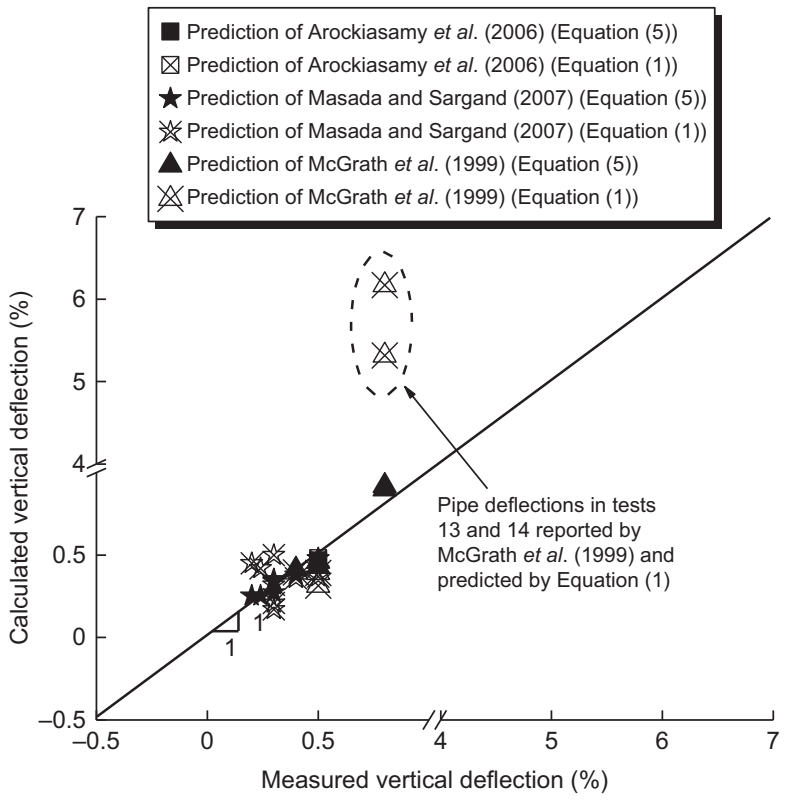

Figure 8. Comparison of the measured and simulated vertical peaking deflections for the vibratory plate compactor via Equations 1 and 5

Geosynthetics International, 2017, 24, No. 4 


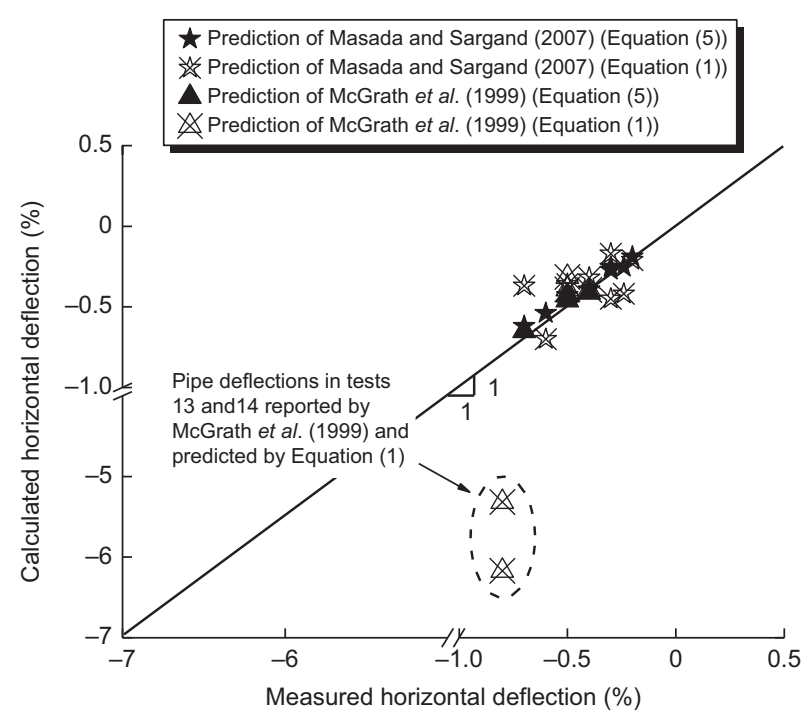

Figure 9. Measured and simulated horizontal peaking deflections for the vibratory plate compactor via Equations 1 and 5

pipe deflection at a given thickness of sidefill in spite of the constant $K_{\mathrm{p}}$ value. The pipe deflection in the vertical direction was approximately equal to that in the horizontal direction with the same pipe stiffness and sidefill thickness. The peaking deflection for the case with a pipe stiffness of $107 \mathrm{kPa}$ was $0.45 \%$, and that for the case with a pipe stiffness of $860 \mathrm{kPa}$ was $0.35 \%$. The peaking deflection decreased by $22 \%$ when the pipe stiffness increased from $107 \mathrm{kPa}$ to $860 \mathrm{kPa}$. It is seen that the pipe stiffness significantly influences the peaking deflection.

Figure 5 illustrates the effect of the sidefill type and the degree of compaction on the pipe deflection during the initial backfilling process. For the two cases where sidefill materials had similar relative flexure stiffness (i.e. SW85 $\left(S_{\mathrm{f}}=101\right)$ and CL95 $\left.\left(S_{\mathrm{f}}=115\right)\right)$, the peaking deflections were essentially the same, with less than $0.5 \%$ difference, regardless of considerably different $K_{\mathrm{p}}$ value (4.2 for SW85 and 2.77 for CL95). However, the peaking deflection for SW95 $\left(S_{\mathrm{f}}=431\right)$ was $25 \%$ higher than the value for SW85 or CL95. As seen in Table 6, the Young's moduli were 2.64, 1.64 and $6.44 \mathrm{MPa}$ for SW85, CL95 and SW95, respectively. It can be seen that the modulus of SW95 was approximately three times that of SW85 or CL95. Therefore, it is concluded that the soil modulus is an essential parameter for the peaking deflection.

Figure 6 presents the effect of the trench width on the pipe deflection during the initial backfilling process. When the trench width increased from 0.8 to $2.0 \mathrm{~m}$, the differences for both the vertical and horizontal deflections were less $5 \%$. Consequently, it is concluded that the trench width has a minor effect on the peaking deflection.

Figure 7 shows the effect of the compactor type on the pipe deflection during the initial backfilling. As suggested by Elshimi and Moore (2013), the kneading factors, $K_{\mathrm{n}}$, were 1.0 and 2.0 for vibratory plate and rammer compactors, respectively. In other words, the magnitude of the applied horizontal point loads for the case using a rammer compactor was two times that for the case using

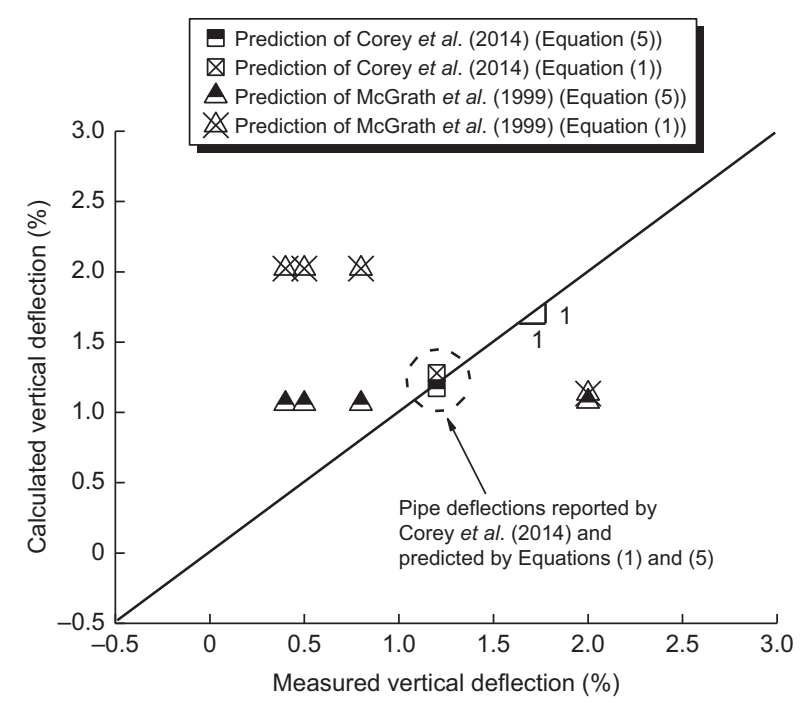

Figure 10. Measured and simulated vertical peaking deflections for the rammer compactor via Equations 1 and 5

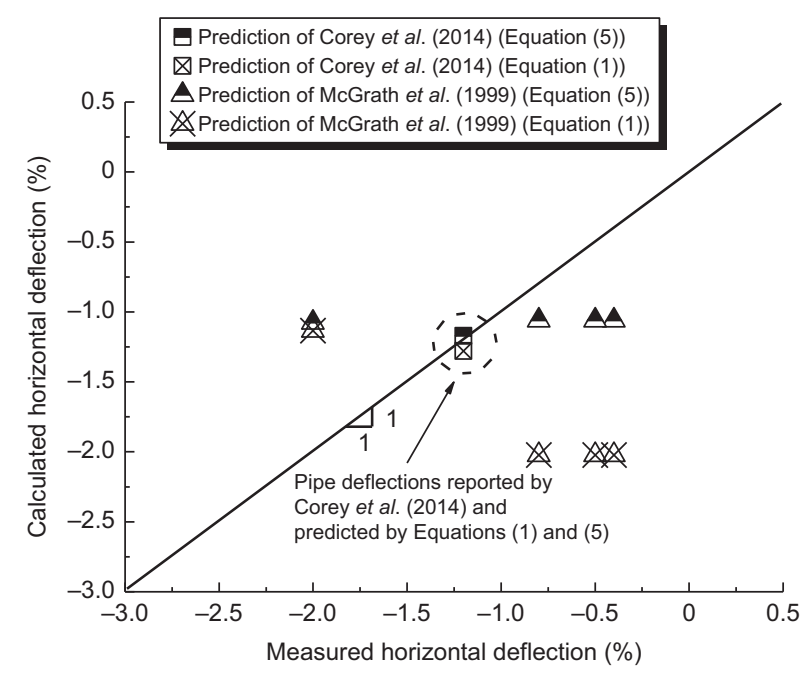

Figure 11. Measured and simulated horizontal peaking deflections for the rammer compactor via Equations 1 and 5

Table 7. Input parameters used for calculation of peaking deflections of pipes in the field test

\begin{tabular}{|l|c|c|c|}
\hline \multirow{2}{*}{ Parameter } & \multicolumn{3}{|c|}{ Value } \\
\cline { 2 - 4 } & P1 pipe & P2 pipe & P3 pipe \\
\hline$D(\mathrm{~m})$ & 0.6 & 0.6 & 0.3 \\
$\mathrm{PS}(\mathrm{kPa})$ & 215 & 215 & 215 \\
$M_{\mathrm{s}}{ }^{\mathrm{a}}(\mathrm{MPa})$ & 3.68 & 3.68 & 3.68 \\
$P_{\mathrm{c}}$ & 0.207 & 0.207 & 0.207 \\
$K_{\mathrm{o}}$ & 0.47 & 0.47 & 0.47 \\
$\gamma\left(\mathrm{kN} / \mathrm{m}^{3}\right)$ & 20.2 & 20.2 & 20.2 \\
\hline
\end{tabular}

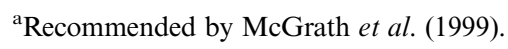

the vibratory plate compactor. It is seen that the peaking deflection for the rammer compactor was $0.9 \%$, while that for the vibratory compactor was $0.4 \%$. The average ratio of pipe deflections generated by the rammer to those by 
Table 8. Input parameters used for calculation of peaking deflections in tests reported by McGrath et al. (1999)

\begin{tabular}{|c|c|c|c|c|c|c|c|c|c|c|}
\hline \multirow[t]{2}{*}{ Parameter } & \multicolumn{10}{|c|}{ Value } \\
\hline & Test 1 & Test 3 & Test 4 & Test 6 & Test 7 & Test 8 & Test 9 & Test 11 & Test 13 & Test 14 \\
\hline$D(\mathrm{~m})$ & 1.1 & 1.1 & 1.1 & 1.1 & 1.1 & 1.1 & 1.1 & 1.1 & 1.7 & 1.7 \\
\hline $\mathrm{PS}(\mathrm{kPa})$ & 390 & 390 & 390 & 390 & 390 & 390 & 390 & 390 & 36 & 36 \\
\hline$M_{\mathrm{s}}(\mathrm{MPa})$ & 13.06 & 13.06 & 7.58 & 13.8 & 8.78 & 13.8 & 13.06 & 7.58 & 7.58 & 7.58 \\
\hline Compactor & Rammer & Rammer & $\begin{array}{c}\text { Vibratory } \\
\text { plate }\end{array}$ & Rammer & $\begin{array}{c}\text { Vibratory } \\
\text { plate }\end{array}$ & Rammer & Rammer & $\begin{array}{c}\text { Vibratory } \\
\text { plate }\end{array}$ & $\begin{array}{c}\text { Vibratory } \\
\text { plate }\end{array}$ & $\begin{array}{c}\text { Vibratory } \\
\text { plate }\end{array}$ \\
\hline$P_{\mathrm{c}}(\mathrm{kPa})$ & 5.51 & 5.51 & 0.4 & 2.69 & 0.207 & 2.69 & 5.51 & 0.4 & 0.4 & 0.207 \\
\hline & 0.41 & 0.41 & 0.41 & 0.53 & 0.53 & 0.53 & 0.41 & 0.41 & 0.41 & 0.53 \\
\hline$\gamma\left(\mathrm{kN} / \mathrm{m}^{3}\right)$ & 20.7 & 20.7 & 19.3 & 15.4 & 14.3 & 15.4 & 20.7 & 19.3 & 19.3 & 14.3 \\
\hline
\end{tabular}

Note: HDPE pipes are used in all the test cases 1 to 14, but data for test cases 2, 5,10 and 12 are not available.

the vibratory plate compactor is 2.4. Therefore, the compactor type has a significant effect on the peaking deflection.

\section{PROPOSED EMPIRICAL FORMULA AND ITS VALIDATION}

\subsection{Proposed empirical formula}

Based on the numerical results, the pipe diameter, the pipe stiffness, the soil modulus and the compactor type are found to have more significant effects on the peaking deflection compared to the trench width. The effects of pipe stiffness and soil modulus can be represented by the relative flexure stiffness. In addition, the magnitude of pipe deflections in both the vertical and the horizontal directions during the initial backfilling increases approximately linearly with the thickness of the sidefill, as shown in Figure 3 through Figure 7.

Based on linear regression, an empirical equation is obtained by linking pipe deflection with the relative flexure stiffness, the type of the compactor and the thickness of the sidefill as follows

$$
\Delta y / D=-\Delta x / D=\left(0.05 S_{\mathrm{f}}+33\right) \eta H^{\prime} /(10000 D)
$$

where $\Delta y / D$ and $\Delta x / D$ are the peaking deflections in the vertical and the horizontal directions, respectively; $S_{\mathrm{f}}$ is the relative flexure stiffness; $\eta$ is an empirical constant related to the compactor type, which is 1.0 and 2.4 for the vibratory plate and the rammer compaction methods, respectively; $H^{\prime}$ is the height of the soil fill placed at the lateral side of the pipe from the pipe invert (m); and all other parameters and their units are the same as those defined in Equation 1. The coefficient of determination, $R^{2}$, is 0.96 . It is concluded from Figures 4 and 5 that relative flexure stiffness $\left(S_{\mathrm{f}}\right)$ has a more significant effect on the peaking deflection than $K_{\mathrm{p}}$. Therefore, the $S_{\mathrm{f}}$ is included in Equation 5 rather than the $K_{\mathrm{p}}$.

\subsection{Validation of proposed formulas}

McGrath et al. (1999), Arockiasamy et al. (2006), Masada and Sargand (2007) and Corey et al. (2014) reported field and laboratory investigations into the peaking deflection of HDPE pipes. Their data were used to evaluate the proposed method (i.e. Equation 5). In Figures 8-11, comparisons are presented of the predicted peaking deflections of the pipe between the Masada and Sargand (2007) method (Equation 1) and the proposed method using the data reported in the literature. The values of input parameters used in the Masada and Sargand (2007) and the proposed method in this study are shown in Tables 7-11. Krizek et al. (1971) found that the constrained soil modulus $M_{\mathrm{s}}$ could be 0.7 to 1.5 times the soil reaction modulus $E^{\prime}$. Hartley and Duncan (1987) and McGrath (1998) pointed out $E^{\prime}$ can be treated as equal to $M_{\mathrm{s}}$. In this study, $E^{\prime}=M_{\mathrm{s}}$ is adopted to simplify the analysis.

Figure 8 shows that the peaking deflections in the vertical direction calculated using Equation 1 proposed by Masada and Sargand (2007) agree well with the measured data reported by McGrath et al. (1999) (tests 4, 7 and 11), Arockiasamy et al. (2006) and Masada and Sargand (2007). The range of relative error is from $9 \%$ to $20 \%$. However, values of pipe deflection predicted by Equation 1 are six to eight times those measured in tests 13 and 14 in McGrath et al. (1999) (data points circled by a dashed line). The peaking deflections predicted by the proposed method, that is, Equation 5, in this study, match well with all the data reported by McGrath et al. (1999), Arockiasamy et al. (2006) and Masada and Sargand (2007) with relative errors of less than $10 \%$.

Figure 9 presents the peaking deflections in the horizontal direction calculated using Equation 1, proposed by Masada and Sargand (2007), which are in good agreement with those reported by McGrath et al. (1999) (tests 4, 7, and 11) and Masada and Sargand (2007) with a range of relative error of $5 \%$ to $15 \%$ and $10 \%$ to $21 \%$, respectively. However, the predicted values are five to six times those measured in tests 13 and 14 reported by McGrath et al. (1999) (data points circled by dashed line).

Table 9. Input parameters used for calculation of peaking deflections in tests reported by Arockiasamy et al. (2006)

\begin{tabular}{|l|c|c|c|c|c|c|}
\hline Parameter & $\begin{array}{c}\mathrm{PS} \\
(\mathrm{kPa})\end{array}$ & $\begin{array}{c}M_{\mathrm{s}}^{\mathrm{a}} \\
(\mathrm{MPa})\end{array}$ & $\begin{array}{c}D \\
(\mathrm{~m})\end{array}$ & $\begin{array}{c}\gamma \\
\left(\mathrm{kN} / \mathrm{m}^{3}\right)\end{array}$ & $K_{\mathrm{o}}$ & $\begin{array}{c}P_{\mathrm{c}}^{\mathrm{b}} \\
(\mathrm{kPa})\end{array}$ \\
\hline Value & 238 & 9.76 & 1.34 & 20 & 0.34 & 0.207 \\
\hline
\end{tabular}

${ }^{\mathrm{a}, \mathrm{b}}$ Recommended by McGrath et al. (1999). 
Table 10. Input parameters used for peaking deflections in tests reported by Masada and Sargand (2007)

\begin{tabular}{|l|c|c|c|c|c|c|c|c|c|c|}
\hline \multirow{2}{*}{ Parameter } & \multicolumn{10}{|c|}{ Value } \\
\cline { 2 - 11 } Pipe number & P7 & P8 & P9 & P12 & P13 & P14 & P15 & P16 & P17 & P18 \\
\hline PS $(\mathrm{kPa})$ & 246 & 244 & 168 & 243 & 211 & 211 & 211 & 128 & 128 & 128 \\
$M_{\mathrm{s}}^{\mathrm{a}}(\mathrm{MPa})$ & 13.78 & 13.78 & 7.56 & 16.88 & 10.47 & 13.78 & 15.85 & 13.06 & 16.88 & 13.78 \\
$P_{\mathrm{c}}^{\mathrm{b}}(\mathrm{kPa})$ & 0.207 & 0.207 & 0.41 & 0.41 & 0.207 & 0.207 & 0.41 & 0.41 & 0.41 & 0.207 \\
$r(\mathrm{~m})$ & 0.41 & 0.41 & 0.41 & 0.41 & 0.57 & 0.57 & 0.57 & 0.8 & 0.8 & 0.8 \\
$\gamma\left(\mathrm{kN} / \mathrm{m}^{3}\right)$ & 18.95 & 19.1 & 19.6 & 21.48 & 17.77 & 18.2 & 20.05 & 20.1 & 21.59 & 18.09 \\
$K_{\mathrm{o}}$ & 0.29 & 0.39 & 0.31 & 0.28 & 0.34 & 0.29 & 0.33 & 0.33 & 0.28 & 0.29 \\
\hline
\end{tabular}

Note: P1 to P6 pipes were PVC pipe and P10 and P11 pipes were unavailable.

${ }^{\mathrm{a}, \mathrm{b}}$ Recommended by McGrath et al. (1999).

Table 11. Input parameters used for calculation of peaking deflections in tests reported by Corey et al. (2014)

\begin{tabular}{|l|c|c|c|c|c|c|}
\hline Parameter & $\begin{array}{c}\mathrm{PS} \\
(\mathrm{kPa})\end{array}$ & $\begin{array}{c}M_{\mathrm{s}}^{\mathrm{a}} \\
(\mathrm{MPa})\end{array}$ & $\begin{array}{c}D \\
(\mathrm{~m})\end{array}$ & $\begin{array}{c}\gamma \\
\left(\mathrm{kN} / \mathrm{m}^{3}\right)\end{array}$ & $K_{\mathrm{o}}$ & $\begin{array}{c}P_{\mathrm{c}}^{\mathrm{b}} \\
(\mathrm{kPa})\end{array}$ \\
\hline Value & 294 & 13.8 & 0.642 & 18.1 & 0.34 & 2.69 \\
\hline
\end{tabular}

Note: steel-reinforced HDPE pipe was used in the laboratory model test.

${ }^{\mathrm{a}, \mathrm{b}}$ Recommended by McGrath et al. (1999).

The peaking deflection in the horizontal direction calculated by Equation 5 matches well with all the measured data reported by McGrath et al. (1999) and Masada and Sargand (2007), with a range of lower relative error of $5 \%$ to $10 \%$ and $3 \%$ to $8 \%$, respectively. The vertical and horizontal peaking deflections of the pipe calculated by the Masada and Sargand (2007) method, that is, Equation 1, do not represent well the data for the tests reported by McGrath et al. (1999), as shown in Figures 8 and 9. A possible reason is that the sidefill modulus and the pipe-soil interface friction are not considered in Equation 1.

Figure 10 illustrates that the peaking deflections in the vertical direction predicted using the proposed method and by the Masada and Sargand (2007) method agree well with the measured data reported by Corey et al. (2014), with a range of relative error of $4 \%$ to $20 \%$. The values calculated using both methods for tests reported by McGrath et al. (1999) do not match well with the measured data. Nevertheless, the proposed method presents a better quantitative guideline than the Masada and Sargand (2007) method. Further research on this aspect is needed. Figure 11 presents similar comparisons for the peaking deflections in the horizontal direction.

\section{CONCLUSIONS}

2DFE modeling was conducted to investigate the peaking deflections of buried HDPE pipes during the initial backfilling process. The results were evaluated using the field test data. Parametric studies were conducted to investigate the effects of pipe diameter, pipe stiffness, soil modulus, trench width, and compactor type on the peaking deflections of the pipes. It is seen that pipe diameter, pipe stiffness, soil modulus and compactor type have a significant effect on the peaking deflection and their influences need to be included into deflection computations. Meanwhile, the influence of the trench width was found to be insignificant and can be omitted. An empirical formula is proposed for estimating the peaking deflection of buried HDPE pipes

$$
\Delta y / D=-\Delta x / D=\left(0.05 S_{\mathrm{f}}+33\right) \eta H^{\prime} /(10000 D)
$$

The proposed equation is verified against field data from the published studies. Compared with the method proposed by Masada and Sargand (2007), valuable improvement in prediction is achieved and the proposed equation can provide a useful tool for geotechnical engineering practice.

\section{ACKNOWLEDGEMENTS}

The authors are grateful for the financial support from the National Natural Science Foundation of China (Grant No. 51108078, 51278100 and 41472258), Natural Science Foundation of Jiangsu Province (Grant No. BK20131294 and BK2012022), the Fundamental Research Funds for the Central Universities, Colleges and Universities in Jiangsu Province Plans to Graduate Research and Innovation (Grant No. KYLX_0144), and the Scientific Research Foundation of Graduate School of Southeast University (Grant No. YBJJ1632). The authors also express their gratitude to graduate students X. G., Qin, Q. You, D. D. Dong, and P. C. Wang at Southeast University for their assistance in conducting the field test.

\section{NOTATION}

Basic SI units are given in parentheses.

$A$ cross-sectional area of the pipe wall per unit length $\left(\mathrm{m}^{2} / \mathrm{m}\right)$

$D$ undeformed diameter of the pipe (m)

$\mathrm{d} x$ horizontal diameter change/un-deformed pipe diameter (dimensionless)

$\mathrm{dy}$ vertical diameter change/un-deformed pipe diameter (dimensionless) 
$E \quad$ Young's modulus of pipe material (Pa)

$E_{0} \quad$ elastic soil modulus at the reference position $(\mathrm{Pa})$

$E_{\text {increment }}$ increase of soil modulus per unit of depth $(\mathrm{Pa})$

$H^{\prime} \quad$ sidefill thickness (m)

I moment of inertia of pipe wall per unit length $\left(\mathrm{m}^{4} / \mathrm{m}\right)$

$K_{0} \quad$ lateral earth pressure coefficient at rest (dimensionless)

$K_{\mathrm{n}} \quad$ kneading factor (dimensionless)

$K_{\mathrm{p}}$ passive earth pressure coefficient (dimensionless)

$M_{\mathrm{s}}$ constrained soil modulus $(\mathrm{kPa})$

$P_{\mathrm{c}} \quad$ lateral pressure generated by the compactor $(\mathrm{Pa})$

PS pipe stiffness $(\mathrm{kPa})$

$R^{2} \quad$ coefficient of determination (dimensionless)

$R_{\text {inter }}$ strength reduction factor (dimensionless)

$r$ radius of the undeformed pipe (m)

$S_{\mathrm{f}} \quad$ relative flexure stiffness (dimensionless)

$z$ depth of backfill (m)

$\gamma \quad$ unit weight of the sidefill $\left(\mathrm{N} / \mathrm{m}^{3}\right)$

$\Delta x$ pipe diameter change in the horizontal direction $(\mathrm{m})$

$\Delta y \quad$ pipe diameter change in the vertical direction $(\mathrm{m})$

$\eta \quad$ an empirical constant related to the compactor type (dimensionless)

$\sigma_{\mathrm{h}}$ horizontal pressure imposed on the pipe side $(\mathrm{Pa})$

$\sigma_{\mathrm{v}} \quad$ soil layer overburden pressure $(\mathrm{Pa})$

$v$ Poisson's ratio (dimensionless)

\section{ABBREVIATIONS}

2DFE two-dimensional finite-element

AASHTO American Association of State Highway and Transportation Officials

ASTM American Society for Testing and Materials

CECS China Association for Engineering Construction Standardization

CL95 low plasticity clay with a degree of compaction of $95 \%$

HDPE high-density polyethylene

SW85 well-graded sand with a degree of compaction of $85 \%$

SW95 well-graded sand with a degree of compaction of $95 \%$

\section{REFERENCES}

AASHTO (American Association of State Highway and Transportation Officials) (2012). AASHTO LRFD Bridge Design Specifications, 2nd edn. AASHTO, Washington, DC, USA.

Arockiasamy, M., Chaallal, O. \& Limpeteeprakarn, T. (2006). Full-scale field tests on flexible pipes under live load application. Journal of Performance of Constructed Facilities, 20, No. 1, 21-27.
ASTM D1556-07 Standard Test Method for Density and Unit Weight of Soil in Place by the Sand-Cone Method. ASTM International, West Conshohocken, PA, USA.

ASTM D2321-11 Standard Practice for Underground Installation of Thermoplastic Pipe for Sewers and Other Gravity-Flow Applications. ASTM International, West Conshohocken, PA, USA.

ASTM D3080-11 Standard Test Method for Direct Shear Test of Soils under Consolidated Drained Conditions. ASTM International, West Conshohocken, PA, USA.

Bathurst, R. J., Allen, T. M. \& Walters, D. L. (2002). Short-term strain and deformation behavior of geosynthetic walls at working stress conditions. Geosynthetics International, 9, No. 5-6, 451-482.

Bolton, M. D. (1986). The strength and dilatancy of sands. Geotechnique, 36, No. $1,65-78$.

Brachman, R. W. I., Moore, I. D. \& Munro, S. M. (2008). Compaction effects on strains within profiled thermoplastic pipes. Geosynthetics International, 15, No. 2, 72-85.

Brinkgreve, R. B. J. (2006). Plaxis: Finite Element Code for Soil and Rock Analyses: 2D-Version 8.5: (User's Guide), Balkema, Delft, the Netherlands.

CECS (China Association for Engineering Construction Standardization) (2004). Technical Specification for Buried PE Pipeline of Sewer Engineering. China Association for Engineering Construction Standardization, China Architecture and Building Press, Beijing, China.

Chua, K. M. (1986). Time-Dependent Interaction of Soil and Flexible Pipe, PhD thesis, Texas A \& M University, College Station, TX, USA.

Corey, R., Han, J., Khatri, D. K. \& Parsons, R. L. (2014). Laboratory study on geosynthetic protection of buried steel-reinforced HDPE pipes from static loading. Journal of Geotechnical and Geoenvironmental Engineering, 140, No. 6, 04014019.

Dhar, A. S., Moore, I. D. \& McGrath, T. J. (2004). Two-dimensional analyses of thermoplastic culvert deformations and strains. Journal of Geotechnical and Geoenvironmental Engineering, 130, No. 2, 199-208.

Elshimi, T. M. \& Moore, I. D. (2013). Modeling the effects of backfilling and soil compaction beside shallow buried pipes. Journal of Pipeline Systems Engineering and Practice, 4, No. 4, 04013004.

El-Taher, M. \& Moore, I. D. (2008). Finite element study of stability of corroded metal culverts. Transportation Research Record, 2050, 157-166.

Fleming, P. R., Faragher, E. \& Rogers, C. D. F. (1997). Laboratory and field testing of large-diameter plastic pipe. Transportation Research Record, 1594, 208-216.

Ganesan, S., Kuo, M. \& Bolton, M. (2014). Influences on pipeline interface friction measured in direct shear tests. Geotechnical Testing Journal, 37, No. 1, 1-13.

Giroud, J. P. \& Han, J. (2004). Design method for geogrid-reinforced unpaved roads, part I theoretical development. ASCE Journal of Geotechnical and Geoenvironmental Engineering, 130, No. 8, 776-786.

Han, J., Acharya, R., Parsons, R. \& Khatri, D. (2013). Improved Load Distribution for Load Rating of Low-Fill Box Structures, Final Report submitted. Kansas Department of Transportation, K-TRAN: KU12-3, Lawrence, KS, USA.

Han, J., Wang, F., Khatri, D., Parsons, R. \& Brennan, J. (2015). Establishing a Design Procedure for Buried Steel-Reinforced High-Density Polyethylene Pipes: A Field Study, Final Report submitted. Kansas Department of Transportation, K-TRAN: KU14-4, Lawrence, KS, USA.

Hartley, J. P. \& Duncan, J. M. (1987). E' and its variation with depth. Journal of Transportation Engineering-ASCE, 113, No. 5, 538-553.

Howard, A., Spridzans, J. B. \& Schrock, B. J. (1994). Latvia field test of 915-mm fiberglass pipe. Buried Plastic Pipe Technology, Eckstein, D., Editor, vol. 2, ASTM International, West Conshohocken, PA, USA, pp. 3-21.

Khatri, D. K., Han, J., Corey, R., Parsons, R. L. \& Brennan, J. J. (2015). Laboratory evaluation of installation of a steel-reinforced highdensity polyethylene pipe in soil. Tunnelling and Underground Space Technology, 49, 199-207. 
Krizek, R. J., Parmelee, R. A., Kay, J. N. \& Elnaggar, H. A. (1971). Structural Analysis and Design of Pipe Culverts, NCHRP Report 116. National Research Council, Washington, DC, USA.

Marston, A. \& Anderson, A. O. (1913). The Theory of Loads on Pipes in Ditches: Tests of Cement and Clay Drain Tile and Sewer Pipe, Iowa State College of Agriculture, Ame, IA, USA.

Masada, T. \& Sargand, S. M. (2007). Peaking deflections of flexible pipe during initial backfilling process. Journal of Transportation Engineering, 133, No. 2, 105-111.

McGrath, T. J. (1998). Replacing $\mathrm{E}^{\prime}$ with the constrained modulus in flexible pipe design. In Proceedings of the Pipeline Division Conference, Castronovo, J. P. and Clark, J. A., Editors, ASCE, San Diego, CA, USA, pp. 28-40.

McGrath, T. J., Selig, E. T., Webb, M. C. \& Zoladz, G. V. (1999). Pipe Interaction with the Backfill Envelope, FHWA-RD-98-191. National Science Foundation, Washington, DC, USA

McGrath, T. J., Selig, E. T., Moore, I. D., Webb, M. C. \& Taleb, B. (2002). Recommended Specifications for Large Span Culverts, NCHRP Rep. 473. Transportation Research Board, Washington, DC, USA.

Ni, P. P. (2016). Nonlinear Soil-Structure Interaction for Buried Pressure Pipes under Differential Ground Motion, PhD thesis, Department of Civil Engineering, Queen's University, Kingston, ON, Canada.

O'Rourke, T., Druschel, S. \& Netravali, A. (1990). Shear strength characteristics of sand-polymer interfaces. Journal of Geotechnical Engineering, 116, No. 3, 451-469.

Sargand, S. M., Masada, T. \& Schehl, D. J. (2001). Soil pressure measured at various fill heights above deeply buried thermoplastic pipe. Transportation Research Record, 1770, 227-235.

Sargand, S. M., Hazen, G. A. \& Masada, T. (2002). Field Verification of Structural Performance of Thermoplastic Pipe under Deep Backfill Conditions, FHWA/OH-2002/023, Final Rep. Ohio Dept. of Transportation, Cincinnati, OH, USA.

Sargand, S. M., Masada, T., Tarawneh, B. \& Yanni, H. (2004). Use of soil stiffness gauge in thermoplastic pipe installation. Journal of Transportation Engineering, 130, No. 6, 768-776.

Shen, S. L. \& Xu, Y. S. (2011). Numerical evaluation of land subsidence induced by groundwater pumping in Shanghai. Canadian Geotechnical Journal, 48, No. 9, 1378-1392.

Shen, S. L., Ma, L., Xu, Y. S. \& Yin, Z. Y. (2013). Interpretation of increased deformation rate in aquifer IV due to groundwater pumping in Shanghai. Canadian Geotechnical Journal, 50, No. 11, 1129-1142.

Shen, S. L., Wang, J. P., Wu, H. N., Xu, Y. S., Ye, G. L. \& Yin, Z. Y (2015). Evaluation of hydraulic conductivity for both marine and deltaic deposit based on piezocone test. Ocean Engineering, 110, 174-182.

Shen, S. L., Cui, Q. L., Ho, E. C. \& Xu, Y. S. (2016). Ground response to multiple parallel microtunneling operations in cemented silty clay and sand. Journal of Geotechnical and Geoenvironmental Engineering, 142, No. 5, 04016001

Siddiquee, M. S. A. \& Dhar, A. S. (2015). A novel viscoplastic model of high-density polyethylene pipe material. Geosynthetics International, 22, No. 2, 173-182.

Taleb, B. \& Moore, I. D. (1999). Metal culvert response to earth loading performance of two-dimensional analysis. Transportation Research Record, 1656, 25-36.

Wang, F., Du, Y. J., Zhou, M. \& Zhang, Y. J. (2015). Experimental study of the effects produced by a backfilling process on full-scale buried corrugated HDPE pipes in fine-grained soils. ASCE Journal of Pipeline Systems Engineering and Practice, 7, No. 1, 05015001.

Wijewickreme, D., Amarasinghe, R. \& Eid, H. (2014). Macro-scale direct shear test device for assessing soil-solid interface friction under low effective normal stresses. Geotechnical Testing Journal, 37, No. 1, 1-18.

Witthoeft, A. F. \& Kim, H. (2015). Numerical investigation of earth pressure reduction on buried pipes using EPS geofoam compressible inclusions. Geosynthetics International, 23, No. 4, 287-300.

Xu, Y. S., Ma, L., Shen, S. L. \& Sun, W. J. (2012). Evaluation of land subsidence by considering underground structures penetrated into aquifers in Shanghai. Hydrogeology Journal, 20, No. 8, $1623-1634$.

Zhang, C. \& Moore, I. D. (1997). Finite element modelling of inelastic deformation of ductile polymers. Geosynthetics International, $\mathbf{4}$, No. 2, 137-163.

Zhou, M., Du, Y. J., Zhang, Y. J., Wang, F. \& Qin, X. G. (2015). Variation of soil arching effect during burying process of HDPE pipes. Chinese Journal of Rock Mechanics and Engineering, 34, No. 2, 414 424 (in Chinese).

Zhou, M., Wang, F., Du, Y. J. \& Liu, M. D. (2017). Performance of buried HDPE pipes. Part II: total deflection of the pipe. Geosynthetics International, (accepted).

The Editor welcomes discussion on all papers published in Geosynthetics International. Please email your contribution to discussion@geosynthetics-international.com by 15 February 2018. 